\title{
A Study on the Stress Reduction of Drinking by Measuring Heart Rate Variability
}

\author{
Bong-Young Kim, Uk-Jin Song and Myung-Jin Bae \\ Department of Information and Telecommunication Engineering, Soong-sil University, \\ Sangdo-ro, Dongjak-gu, 369 Seoul, Korea
}

\begin{abstract}
Modern people are exposed to a lot of stress due to intricate social structure and intensified competition. Since, stress is a source of all disease it is very important to stress reduction and overcome it. Too many people drink to stress reduction. While drinking many people rejoice and torment their opponents. The purpose of this study was to investigate the effect of drinking on stress reduce by measuring Heart Rate Variability (HRV) at working and before/after drinking. As a result of the experiment it was confirmed that all the subjects had increased stress index, SDNN before drinking, so that, the stress was reduced. Also, it was confirmed that the stress index increased and some stress index decreased after drinking. The inconsistency in the change in stress index immediately after drinking is a transient phenomenon caused by inhibition of the nervous system. These results show that the drinking party itself helps to reducing the stress rather than drinking alcohol.
\end{abstract}

Key words: Stress, drinking, drinking party, Heart Rate Variability (HRV), SDNN, social structure

\section{INTRODUCTION}

Alcohol was with human history according to gusamguksa, king dongmyong's founding of goguryeo itself is composed of alcohol. In Egyptian mythology there is a way to make beer in the pyramid a wine jar is excavated and also depicted in murals. The impact of alcohol on humans is also very large. Alcohol can not escape most of our rituals. It is no exaggeration to say alcohol is a must in sacrifices and feasts. Alcohol is an essential item in our daily lives and in some ways, alcohol has an overwhelming influence over our lives. Seung Eop Jang (1843-1897) one of the three leading painters of the joseon dynasty, painted the paintings according to good alcohol and personal treatment rather than authority and money and consisted mostly of alcohol, art and wandering for the majority of his life. Vincent van Gogh (1853-1890) a world-renowned painter, enjoyed the abundant alcohol, absinthe to curb the ghastly loneliness and madness. The hallucinogenic symptoms caused by damage to the optic nerve as a component of absinthe's santonin influenced his picture style of brilliant yellow (Moon, 2010; Seal, 2012; Tchai, 1998; Park et al., 2008).

Modern people are exposed to a lot of stress. As the social structure becomes complicated and the competition between each other increases the type and frequency of stress increases and the degree of stress increases. These stresses are the source of all sorts of illness and make the mind and body fragile. The reduction and overcoming of stress is very important. Those who overcome stress can get very successful results from opportunities such as job change or promotion (Moon, 2010; Seal, 2012; Tchai, 1998; Park et al., 2008; Ji-Seon and Myung-Jin, 2013; Lee et al., 2015a, b; Myung-Jin, 2017; Pak et al., 2015).

Alcohol is a very common means of stress reduction. We often meet a friendly person and talk about one's in most thoughts as 'Let's have a drink'. Alcohol is a tool for sharing ideas with people who are accustomed to life when they are tired or depressed, eliminating the gap between people and creating pleasant relationships with each other. Modern people solve the fatigue of the day at the bar and relax the life's happiness and sadness with a glass of alcohol. In most drinking parties, people make happy faces and talk with fun and excited voices. In many literary and artistic scholarly books and books, alcohol also praised the joy of humans (Moon, 2010; Seal, 2012; Tchai, 1998; Park et al., 2008; Ji-Seon and Myung-Jin, 2013; Lee et al., 2015a, b; Myung-jin, 2017; Pak et al., 2015; Bae and Bae, 2017).

Corresponding Author: Myung-Jin Bae, Department of Information and Telecommunication Engineering, Soong-sil University, Sangdo-ro, Dongjak-gu, 369 Seoul, Korea 


\section{MATERIALS AND METHODS}

\section{Changes in body during drinking}

Drinking: When alcohol is consumed, ethanol a major component of alcohol is rapidly absorbed from the stomach and small intestine and is broken down into water and carbon dioxide from the liver which is an energy source but some are excreted when exhaled or excreted in the urine. Drinking suddenly or drinking too much alcohol is harmful to the digestive system, cardiovascular system, central nervous system and can lead to alcohol poisoning (Tchai, 1998; Park et al., 2008).

Changes in body during drinking: In Greek mythology, bacchus is referred to as father of alcohol. A picture depicting bacchus with a blooming face on a glass with wine in one hand symbolically represents a physical change due to drinking. A small amount of drinking improves mood and blood circulation but overeating can cause blood circulation disorders or heart disease. Alcohol can fall asleep if you drink too much alcohol because ethanol suppresses the nerves that control sleep, sleeps well but actually fatigue does not resolve properly. Alcohol acts as an inhibitor to the nervous system making it appear to be excited because it first inhibits the logical thinking part of the brain system. This makes it difficult to distinguish between right and wrong or to be aware of fear or shameful feelings. A large amount of drinking inhibits the thinking circuit and makes the speech disappear. And the movement of the central nervous system is suppressed to lose sense of balance and may fall. In severe cases, the brain's life-sustaining function is inhibited, leading to death (Tchai, 1998; Park et al., 2008).

\section{Heart rate variability and stress index}

Heart rate variability: The heart is composed of two atrium and two ventricles. The action of the myocardium repetitively contracts and relaxes repeatedly. This pumping action causes the five steps to repeat. The heart rate is the number of times the $\mathrm{R}$ phase occurs for $1 \mathrm{~min}$ during the pump action phase of the heart. Figure 1 shows the heartbeat as a reference for the 5 stage pump action and heart rate of the heart (Camm et al., 1996; Park et al., 2008).

Heart rate variability means the degree to which the $\mathrm{N}-\mathrm{N}$ interval, the time interval between $\mathrm{R}$ and $\mathrm{R}$, changes according to the heart beat variable. The ability to control autonomic nerves from a heart beat variable can be estimated. In healthy people, the autonomic nervous

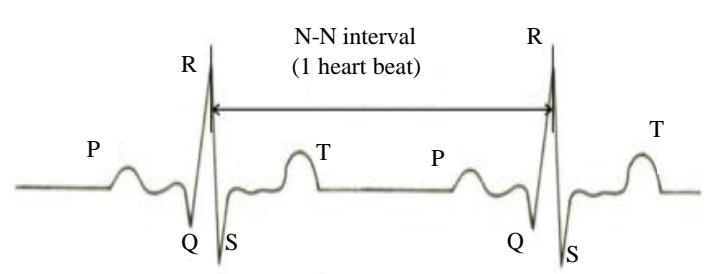

Fig. 1: Five stage pump action of the heart spectrum

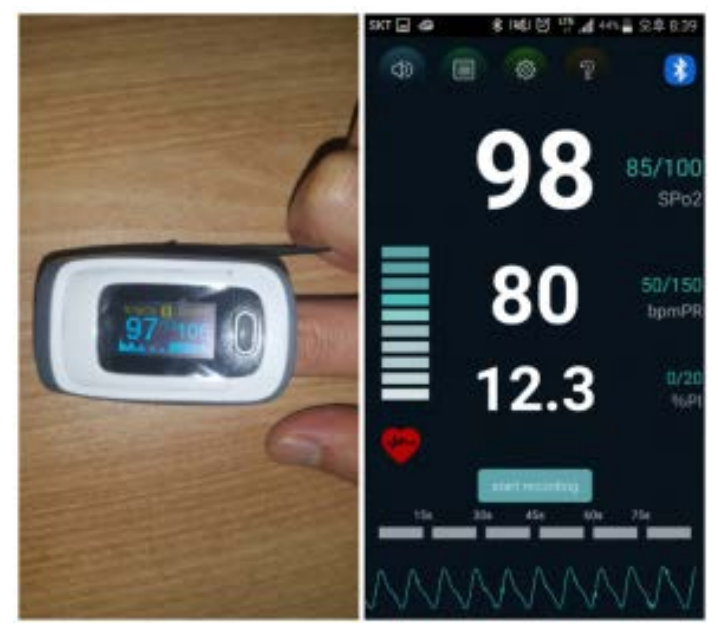

Fig. 2: Pulse oximeter and heart rate variability measurement/recording

Table 1: Relationship between SDNN and stress (Park et al., 2008)

\begin{tabular}{|c|c|}
\hline SDNN & Stress condition \\
\hline 50 or more & $\begin{array}{l}\text { Very good "Autonomic nervous system regulation } \\
\text { function" and "Ability to cope with stress" are good }\end{array}$ \\
\hline $35 \sim 50$ & $\begin{array}{l}\text { General "Autonomic nervous sy stem regulation } \\
\text { function" and "Ability to cope with stress" are normal }\end{array}$ \\
\hline $20 \sim 35$ & $\begin{array}{l}\text { Lowness, risk of developing stress-related diseases } \\
\text { Weakening of autonomic nervous sy stem function }\end{array}$ \\
\hline$<20$ & $\begin{array}{l}\text { Very low there is a high risk of chronic stress disorders } \\
\text { associated with dysfunction of the autonomic } \\
\text { nervous system }\end{array}$ \\
\hline
\end{tabular}

system responds rapidly to changes in oxygen concentration, blood pressure, body temperature and external temperature and the heart rate changes rapidly but in the unhealthy person, the autonomic nervous system responds insensitively to less change in heart rate (Camm et al., 1996; Park et al., 2008; Lee et al., 2015a, b; Bae et al., 2017) (Table 1 and Fig. 2).

In this study, heart rate variability was measured using a generalized smart device and a pulse oximeter. The pumping action of the heart acts as an acceleration of the flow of blood flow which changes the blood flow of the peripheral blood vessels whenever the heart beats. Pulse oximeter is a simple device that measures the heart rate by optical change in the non-invasive way through the finger 
with respect to the blood flow change of peripheralblood vessels. The heart rate variability can be inverselyderived from the measured heart rate using a pulse oximeter. Figure 2 shows the pulse oximeter and recording method measuring the heart rate variability before and after drinking in the experiment.

Relationship between heart rate variability and stress: In 1996, the "Task Force of the European Society of Cardiology and the North American Society of Pacing and Electrophysiology" presented guidelines on methods and standards for analyzing Heart Rate Variability (HRV). This is still an important indicator of heart rate measurement and utilization. SDNN (Standard Deviation N-N interval) is used as a stress index through Heart Rate Variability (HRV). The SDNN can be obtained from the standard deviation of the N-N interval which is the 5th pump action period of the heart. At this time, the N-N interval can be confirmed by the reciprocal of the heart rate. The relationship between SDNN and stress is shown in Table 1. The lower the SDNN, the higher the stress. The higher the SDNN, the lower the stress. The method of calculating the SDNN of the heart rate variability is shown in Eq. 1 (Camm et al., 1996; Park et al., 2008; Lee et al., 2015a, b; Bae et al., 2017):

$$
\operatorname{SDNN}(\sigma)=\sqrt{\sum_{\mathrm{k}=1}^{\mathrm{n}}\left(\mathrm{x}_{\mathrm{k}}-\mu\right)^{2}}
$$

Where:

$\mathrm{x}_{\mathrm{k}}=\mathrm{K}$ 's N-N interval

$\mu=\mathrm{N}-\mathrm{N}$ interval's mean

\section{RESULTS AND DISCUSSION}

The heart rate test was conducted to examine whether drinking was helpful for stress reduction. Six healthy adults (20-40 years old) who did not refuse to drink were evaluated. The 6 male adults measured heart rate at research before drinking, measured heart rate just before drinking and measured heart rate after drinking for about $30 \mathrm{~min}$. They drank $1,000-2,000 \mathrm{~mL}$ of beer/person, so as not to over-drink, considering the amount of personal drinking volume. Experiment participants measured the heart rate without talking and without moving. The procedure for comparing heart rate measurements and changes in SDNN is shown in Fig. 3.

Figure 4 is a graph showing how the heart rate of subject M-1 at working and before/after drinking changes. In Fig. 4, the heart rate did not change much at at working but before heart rate change was greater than at working time. And it can be seen that the change of heart rate is slightly decreased in after drinking compared with before drinking. Table 2 shows the experimental results of 6 male subjects. The N-N interval was calculated from the heart rate data of 6 subjects at working and before/after drinking and SDNN was calculated by this.

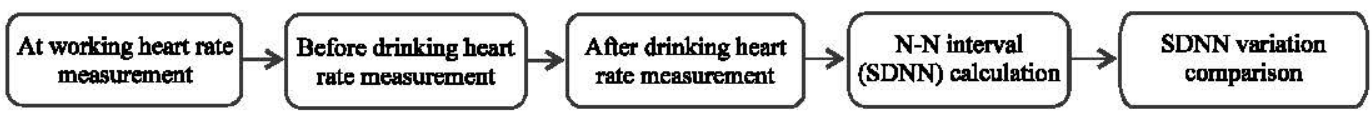

Fig. 3: Heart rate measurement and SDNN comparison procedure

(a)

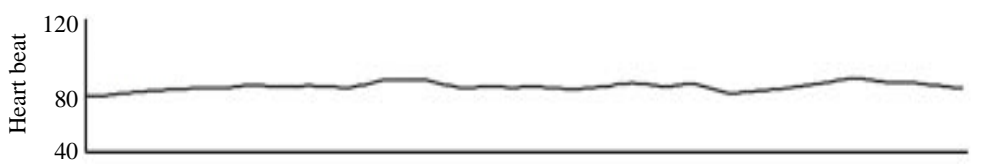

(b)
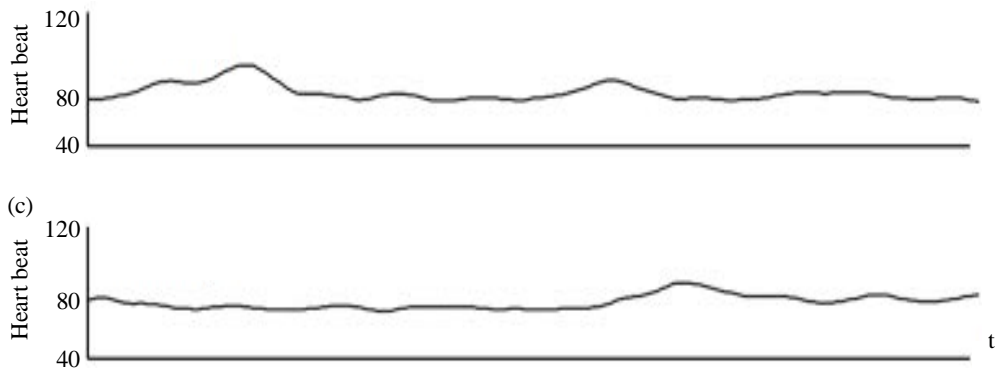

Fig. 4: Comparison of changes in heart rate: a) At working; b) Before drinnking and c) After drinnking 
Table 2: SDNN calculation result

\begin{tabular}{|c|c|c|c|c|}
\hline$\underline{\text { Subject/measurement state }}$ & Average heart rate & Average N-N interval & $\operatorname{SDNN}(\sigma)$ & At working vs. SDNN increase/decrease \\
\hline \multicolumn{5}{|l|}{ M-1 } \\
\hline At working & 70 & 857.14 & 24.79 & \\
\hline Before drinking & 63 & 952.38 & 46.12 & +21.33 \\
\hline After drinking & 77 & 779.22 & 37.67 & +12.88 \\
\hline \multicolumn{5}{|l|}{ M-2 } \\
\hline At working & 112 & 535.71 & 10.59 & \\
\hline Before drinking & 101 & 594.06 & 15.56 & +4.97 \\
\hline After drinking & 102 & 588.24 & 15.74 & +5.15 \\
\hline \multicolumn{5}{|l|}{ M-3 } \\
\hline At working & 77 & 779.22 & 25.61 & \\
\hline Before drinking & 68 & 882.35 & 46.09 & +20.48 \\
\hline After drinking & 79 & 759.49 & 75.57 & +49.96 \\
\hline \multicolumn{5}{|l|}{ M-4 } \\
\hline At working & 73 & 821.92 & 35.03 & \\
\hline Before drinking & 69 & 869.57 & 35.46 & +0.43 \\
\hline After drinking & 73 & 821.92 & 54.59 & +19.56 \\
\hline \multicolumn{5}{|l|}{ M-5 } \\
\hline At working & 89 & 674.16 & 34.85 & \\
\hline Before drinking & 79 & 759.49 & 55.28 & +20.43 \\
\hline After drinking & 82 & 731.71 & 46.57 & +11.72 \\
\hline \multicolumn{5}{|l|}{ M-6 } \\
\hline At working & 77 & 779.22 & 28.26 & \\
\hline Before drinking & 68 & 882.35 & 35.33 & +7.07 \\
\hline After drinking & 79 & 759.49 & 48.26 & +20.00 \\
\hline
\end{tabular}

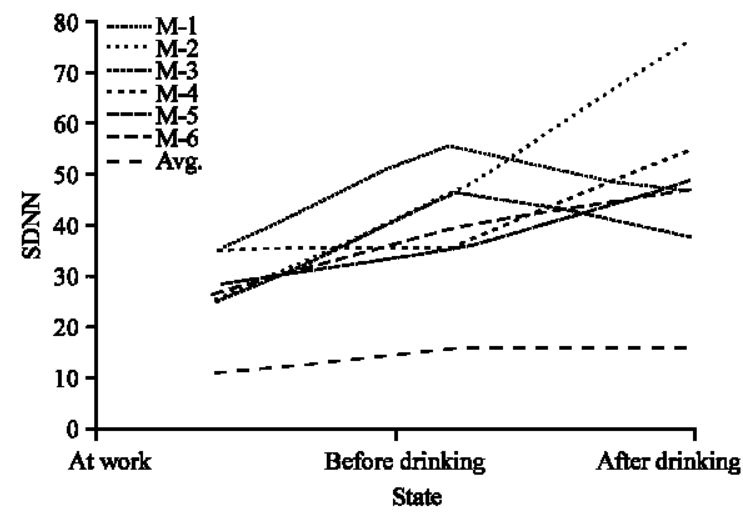

Fig. 5: Changes in SDNN at working and before/after drinking

Figure 5 is a graph showing the change of SDNN value per subject. In Fig. 5, SDNN levels were increased in both before and after drinking compared to working time. Especially, before drinking SDNN values were increased in all subjects during work. However, in the comparison of SDNN values of before and after drinking, 3 patients showed increase in after drinking SDNN, 2 patients showed decrease in SDNN and 1 patient had similar before and after drinking.

\section{CONCLUSION}

Stress is a physical and mental side effect that necessarily accompanies modern living. This stress must be reduced because it is a source of panicky disease. Drinking is what most modern people do to reduce stress.
Alcohol is a very friendly food for humans. Many people drink alcohol to reduce their stress or to reduce the stress of others. We investigated the effects of drinking on stress reduction through experiments. As a result of the experiment we found that the SDNN level measured before drinking in the drinking party was higher than that of the SDNN measured in the workplace. However, after drinking in the drinking party the SDNN results showed that 3 patients were increased, 2 patients were decreased and 1 patient was not significantly changed compared to before drinking. The inconsistency in the results of SDNN measurements after drinking is an individual difference in drinking or a transient phenomenon in which our brain is not controlled by the nervous system due to the inhibition of alcohol. The results of this experiment confirmed that drinking itself is a factor that can increase stress than before drinking and the results of before drinking test showed that stress is reduced for all subjects. This can be said to be a result of the drinking party itself sharing the harshness of life with good people through alcohol as a mediator whether drinking alcohol or not and helping with stress reduction. For most modern people a drinking party is the most common way to overcome stress. However, excessive drinking can cause more stress. Efforts to live healthy without stress through proper drinking culture are needed.

\section{REFERENCES}

Bae, S.G. and M.J. Bae, 2017. A study on recovery in voice analysis through vocal changes before and after specch using speech signal processing. Intl. J. Appl. Eng. Res., 12: 5299-5303. 
Bae, S.G., W.H. Lee and M.J. Bae, 2017. A judgment of intoxication using Hybrid Analysis with Pitch Contour Compare (HAPCC) in speech signal processing. Intl. J. Appl. Eng. Res., 12: 2342-2346.

Camm, A.J., M. Malik, J.T. Bigger, G. Breithardt and S. Cerutti et al., 1996. Heart rate variability: Standards of measurement, physiological interpretation and clinical use. Eur. Heart J., 17: 354-381.

Ji-Seon, H. and B. Myung-Jin, 2013. A study on the classic music for stress reduction. Proc. Acoust. Soc. Korea Conf., 32: 64-65.

Lee, W.H., M.S. Kim and M.J. Bae, 2015. Using valid-frame deviation to judgment of intoxication. Intl. Inf. Instit. Tokyo Inf., 18: 4131-4136.

Lee, W.H., S.G. Bae and M.J. Bae, 2015. A study on improving the overloaded speech waveform to distinguish alcohol intoxication using spectral compensation. Intl. J. Eng. Technol., 7: 1957-1964.
Moon, J.H., 2010. Soju, the bliss of communication and deviation. Master Thesis, Chung-Ang University, Seoul, South Korea.

Myung-Jin, B., 2017. On a voice health technology. J. Acoust. Soc. Korea, 34: 3-4.

Pak, S.Y., M.S. Kim and M.J. Bae, 2015. Acoustic characteristics of sounds in the forest. Intl. Inf. Inst. Tokyo Inf., 18: 4115-4122.

Park, Y.S., S.J. Kim and J.D. Kim, 2008. A study of the relationship between drinking, smoking and stress of workers by analyzing heart rate variability. J. Korean Orient. Med., 29: 134-145.

Seal, B., 2012. Academic Encounters: Human Behavior. Cambridge University, Cambridge, England, UK.

Tchai, B.S., 1998. Nutrition Dictionary. Academy Books, Korea. 